\title{
Early clinical outcomes of a novel self-expanding transapical transcatheter aortic valve bioprosthesis
}

\author{
Michael W. A. Chu, MD, FRCSC, ${ }^{\text {a }}$ Rodrigo Bagur, MD, PhD, FAHA, ${ }^{b}$ Katie L. Losenno, MSc, ${ }^{a}$ \\ Philip M. Jones, MD, MSc, FRCPC, ${ }^{c, d}$ Pantelis Diamantouros, MD, FRCPC, ${ }^{b}$ Patrick Teefy, MD, FRCPC, ${ }^{b}$ \\ Jill J. Gelinas, MD, FRCSC, ${ }^{a}$ and Bob Kiaii, MD, FRCSC ${ }^{\mathrm{a}}$
}

\begin{abstract}
Objective: Coronary obstruction remains a challenging complication of transcatheter aortic valve replacement; however, a new self-expanding transapical prosthesis may reduce this risk. The purpose of this study was to evaluate the early 1-year outcomes of patients with low coronary heights who received the Acurate TA bioprosthesis (Symetis, Ecublens, Switzerland).
\end{abstract}

Methods: Between May 2014 and April 2015, 30 consecutive patients (aged $85 \pm 6$ years, $63 \%$ were female, Society of Thoracic Surgeons score $8.4 \pm 6.0$ ) with severe, symptomatic aortic stenosis underwent transcatheter aortic valve replacement with the Acurate TA bioprosthesis. Relevant patient characteristics included reoperation in $47 \%(\mathrm{n}=14)$, peripheral vascular disease in $43 \%$ $(\mathrm{n}=13)$, and porcelain aorta in $30 \%(\mathrm{n}=9)$. The mean left and right coronary heights were $10.8 \pm 1.5 \mathrm{~mm}$ and $16.4 \pm 4.1 \mathrm{~mm}$, respectively, with a sinus of Valsalva : annular ratio of $1.3 \pm 0.8$.

Results: All 30 device implants were successful. The 30-day in-hospital mortality was $3.3 \%(n=1)$, and no patients had coronary obstruction or stroke. One patient $(3.3 \%)$ had apical rupture requiring cardiopulmonary bypass for repair, 1 patient $(3.3 \%)$ had a localized femoral artery dissection, and 1 patient $(3.7 \%)$ required a new pacemaker. There were no other complications. Mean and peak transaortic valve gradients decreased from $59 \pm 17$ and $84 \pm 31 \mathrm{~mm} \mathrm{Hg}$ to $14 \pm 7$ and $28 \pm 12 \mathrm{~mm} \mathrm{Hg}$, respectively $(P<.0005)$. No patients had more than mild paravalvular aortic insufficiency. At 30 days, there were no further complications and $96.7 \%(\mathrm{n}=29)$ were in New York Heart Association class I/II. Survival at 30 days and 1 year was $97 \%$ and $89 \%$, respectively.

Conclusions: The Symetis Acurate TA device demonstrates high procedural success and excellent acute and 1-year patient outcomes. The device allows safe implantation in patients at higher risk for coronary artery obstruction. (J Thorac Cardiovasc Surg 2017;153:810-8)

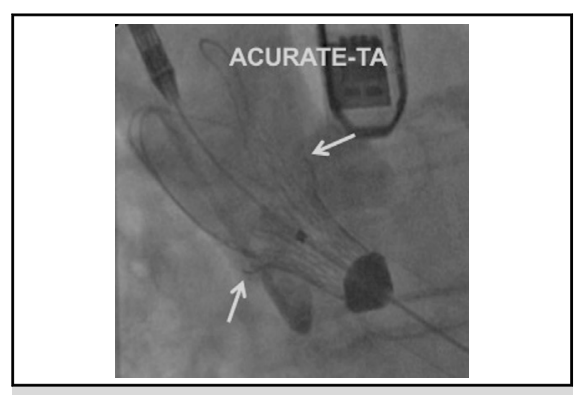

Transcatheter Acurate TA (Symetis, Ecublens, Switzerland) implantation in a patient with low coronary heights.

\section{Central Message}

A new, self-expanding aortic bioprosthesis allows safe transapical TAVR in patients at higher risk of coronary obstruction.

\section{Perspective}

Coronary obstruction after TAVR remains a catastrophic complication with poor patient outcomes. Avoidance of TAVR in patients with high-risk features is common practice; however, newer-generation transapical TAVR designs that engage native aortic valve calcification toward the aortic annulus may have the beneficial effect of reducing the risk of coronary obstruction.

See Editorial Commentary page 819.
From the ${ }^{a}$ Division of Cardiac Surgery, Department of Surgery, ${ }^{b}$ Division of Cardiology, Department of Medicine, ${ }^{\mathrm{c}}$ Department of Anesthesia \& Perioperative Medicine, and ${ }^{\mathrm{d}}$ Department of Epidemiology \& Biostatistics, Western University, Lawson Health Research Institute, London, Ontario, Canada.

Read at the 96th Annual Meeting of The American Association for Thoracic Surgery, May 14-18, 2016, Baltimore, Maryland.

Received for publication June 15, 2016; revisions received Oct 7, 2016; accepted for publication Nov 4, 2016; available ahead of print Jan 7, 2017.

Address for reprints: Michael W. A. Chu, MD, FRCSC, B6-106 University Campus, LHSC, 339 Windermere Rd, London, Ontario N6A 5A5, Canada (E-mail: Michael. Chu@lhsc.on.ca).

$0022-5223 / \$ 36.00$

Copyright (c) 2016 by The American Association for Thoracic Surgery

http://dx.doi.org/10.1016/j.jtcvs.2016.11.054
Coronary obstruction after transcatheter aortic valve replacement (TAVR) remains an uncommon but catastrophic complication associated with significant morbidity and mortality. ${ }^{1-7}$ Female gender, lack of patent coronary

Scanning this $\mathrm{QR}$ code will take you to the supplemental video. To view the AATS 2016 Webcast, see the URL next to the video thumbnail.

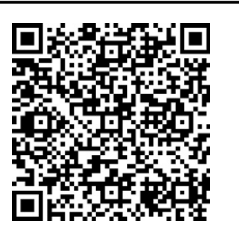




\section{Abbreviations and Acronyms \\ AI = aortic insufficiency \\ $\mathrm{CT}=$ computed tomography \\ NYHA $=$ New York Heart Association \\ TAVR $=$ transcatheter aortic valve replacement}

bypass grafts, use of balloon-expandable device, and valve-in-valve therapy have been described as important patient characteristics for coronary obstruction. ${ }^{1,2,4}$ Anatomic characteristics, including (1) a narrow, tubular aortic root (sinus of Valsalva : aortic annular ratio $<1.3$ ) and (2) low anatomic height between the coronary ostia and the aortic annulus $(<12 \mathrm{~mm})$, are likely the most important risk factors for coronary obstruction after TAVR. ${ }^{1,2,6}$ Clinical presentation often appears first with persistent hypotension, but classic ST elevation is present in only $25 \%$ of the cases. ${ }^{1,2}$ Treatment strategies include emergency coronary stenting, coronary artery bypass or TAVR explant, and surgical aortic valve replacement. Regardless of strategy, overall patient outcomes are poor with $50 \%$ survival at 1 year. $^{2}$ Thus, prevention of coronary obstruction likely is the best strategy with avoidance of TAVR in most patients at higher risk for coronary obstruction.

A newer-generation self-expanding transcatheter valve, the Symetis Acurate TA (Symetis, Ecublens, Switzerland) bioprosthesis, is designed such that it "engages" the calcified native aortic valve down toward the aortic annulus, away from the native coronary arteries that may reduce the risk of coronary obstruction after TAVR. ${ }^{8-13}$ We sought to evaluate the outcomes of TAVR in patients at higher risk for coronary obstruction with the Symetis Acurate TA bioprosthesis.

\section{MATERIALS AND METHODS \\ Population}

Between May 2014 and April 2015, 30 consecutive patients underwent a transapical TAVR with the Symetis Acurate TA bioprosthesis at the University Hospital, London Health Sciences Centre, Western University in London, Ontario, Canada. All patients were assessed by our multidisciplinary heart team and were selected for TAVR on the basis of comorbidities and anatomic or technical details that were considered high risk for surgical aortic valve replacement. Patients with low Society of Thoracic Surgery or European System for Cardiac Operative Risk Evaluation II scores (commonly those with adherent patent internal thoracic artery grafts, porcelain aorta, or severe mediastinal irradiation) needed to be deemed too high risk for conventional surgery by the heart team and 2 additional cardiac surgeons before acceptance for TAVR. Clinical outcomes were evaluated and reported according to the Valve Academic Research Consortium 2 definitions. ${ }^{14}$

\section{Symetis Acurate TA Device}

The Symetis Acurate TA transcatheter valve (Figure 1) is a reconstructed porcine valve within a self-expanding nitinol stent. The stent frame design has 3 stabilization arches to maintain axial alignment of the valve during release. The valve has an "hour-glass" shape with upper and lower crowns that enable tactile feedback during implantation and facilitate axial stabilization of the device and sealing of the left ventricular outflow tract. The device is available only for transapical delivery with 3 commercially available sizes (small, medium, large) to treat aortic annuli diameter between 20 and $27 \mathrm{~mm}$.

\section{Implantation Technique}

All cases were performed in a hybrid operating room under general anesthesia with fluoroscopy and transesophageal echocardiography guidance $^{15}$ by our TAVR team including cardiac surgeons, interventional cardiologists, and cardiac anesthesiologists. A primed cardiopulmonary bypass circuit remained in the room throughout the entire procedure. A standard transapical approach through a 4-cm left anterolateral minithoracotomy with two 2-0 or 3-0 Prolene apical purse-string sutures were used in all patients. ${ }^{16}$ The preoperative TAVR computed tomography (CT) (Figure 2, $A$ and $B$ ) was used to select the optimal orthogonal view for $\mathrm{C}$-arm angulation during implantation. After guidewire placement, balloon aortic valvuloplasty was performed under rapid ventricular pacing using a 20-mm balloon for a small valve, $22-\mathrm{mm}$ balloon for a medium valve, and 25-mm balloon for a large valve. The Acurate TA valve and delivery system were then advanced over the wire into the aortic root and rotated until commissural orientation was achieved. ${ }^{8,9}$ The valve was delivered in a 2-step deployment: (1) The stabilization arches and upper crown were released slightly above the calcified native aortic valve (Figure 2, C) and downward pressure is applied to "engage" the calcified native aortic valve toward the aortic annulus, away from the native coronary ostia (Video 1). (2) The final release/safety pin was removed and the self-expanding valve and lower crown of the prosthesis were deployed, sealing the left ventricular outflow tract with self-adjustment to the axial orientation of the aortic root (Figure 2, D). ${ }^{9}$ After transesophageal echocardiography and fluoroscopic assessment of valve performance, postimplant balloon aortic valvuloplasty was considered for underdeployed prostheses, higher residual gradients, or paravalvular leaks. A completion aortic root angiogram was performed to assess for aortic insufficiency (AI) and coronary obstruction

\section{Follow-up}

All patients underwent standardized transthoracic echocardiograms before discharge from the hospital, at 3 to 6 months, and at 1 year. The patient follow-up was complete in all patients with a mean follow-up of $9.0 \pm 4.3$ months.

\section{Statistics}

All data were prospectively collected in a computerized institutional database and imported to SPSS (IBM Corp, Released 2013. IBM SPSS Statistics for Macintosh, Version 22.0. Armonk, NY: IBM Corp) for statistical analysis. Continuous variables are presented as mean \pm standard deviation or median and interquartile range $(25 \%$, quartile 1 , to $75 \%$, quartile 3 ) as appropriate, and categoric variables are presented as frequencies (percentage). To compare the longitudinal mean and peak aortic valve gradients, a mixed effects model was used to account for the clustering of multiple echocardiographic tests within patients. Likewise, a mixed effects ordinal logistic regression model was used to analyze the longitudinal aortic regurgitation data. The difference in New York Heart Association (NYHA) status before and after valve intervention was compared using a paired ordinal test (the Wilcoxon signed rank-sum test). This study was approved by the institutional research ethics board at Western University, which waived the need for individual patient consent. Individual patient approval for the Symetis Acurate TA device was obtained from Health Canada under the Special Access Program. Each patient provided informed consent before the TAVR procedure acknowledging that they were receiving a TAVR valve not approved by Health Canada. This study represents a retrospective analysis of patients from our center who received a Symetis Acurate TA valve and was not an industry-sponsored trial. Our data were never provided to Symetis, 


\section{Stabilization arches}

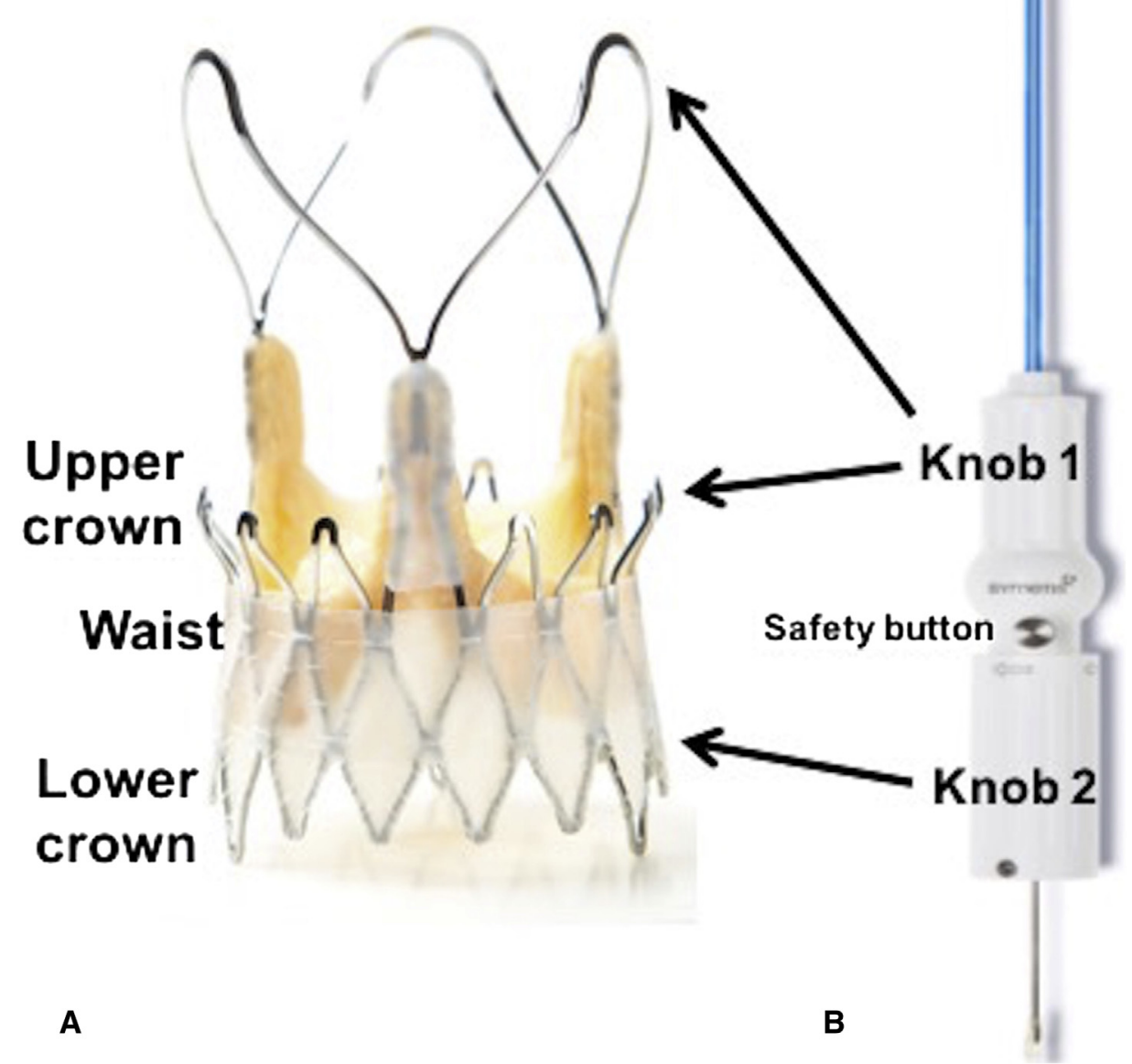

FIGURE 1. The Symetis Acurate TA bioprosthesis (Symetis, Ecublens, Switzerland) (A) with its delivery system (B).

and at no time did Symetis have access to or participate in any aspects of this work.

\section{RESULTS \\ Population}

Patients' mean age was $85 \pm 6$ years, and $63.3 \%$ were female with comorbidities, including diabetes mellitus in 9 patients (30\%), hypertension in 23 patients $(90 \%)$, coronary artery disease in 14 patients $(46.7 \%)$, peripheral vascular disease in 13 patients $(43.3 \%)$, and pulmonary hypertension in 21 patients $(75 \%)$. Nine patients $(30 \%)$ had porcelain aorta, 13 patients $(43.3 \%)$ had prior stroke or transient ischemic attack, and 14 patients $(46.7 \%)$ had prior sternotomy. At the time of operation, all 30 patients
$(100 \%)$ were in NYHA class III or IV, 4 patients $(13.3 \%)$ reported episodes of syncope, and 19 patients $(63.3 \%)$ had angina. The mean Society of Thoracic Surgeons score and European System for Cardiac Operative Risk Evaluation II were $8.4 \pm 6.0$ and $9.7 \pm 7.2$, respectively. Complete patient characteristics and comorbidities are outlined in Table 1.

Comprehensive preoperative echocardiographic and CT details are shown in Table 2. The preoperative mean and peak transvalvular gradients were $59 \pm 17 \mathrm{~mm} \mathrm{Hg}$ and $84 \pm 31 \mathrm{~mm} \mathrm{Hg}$, respectively. Eight patients $(26.7 \%)$ had mild-moderate AI, and 1 patient $(3.3 \%)$ had moderate AI. Dedicated preoperative TAVR CT demonstrated a mean annular diameter of $24.1 \pm 2.1 \mathrm{~mm}$. The mean heights of 

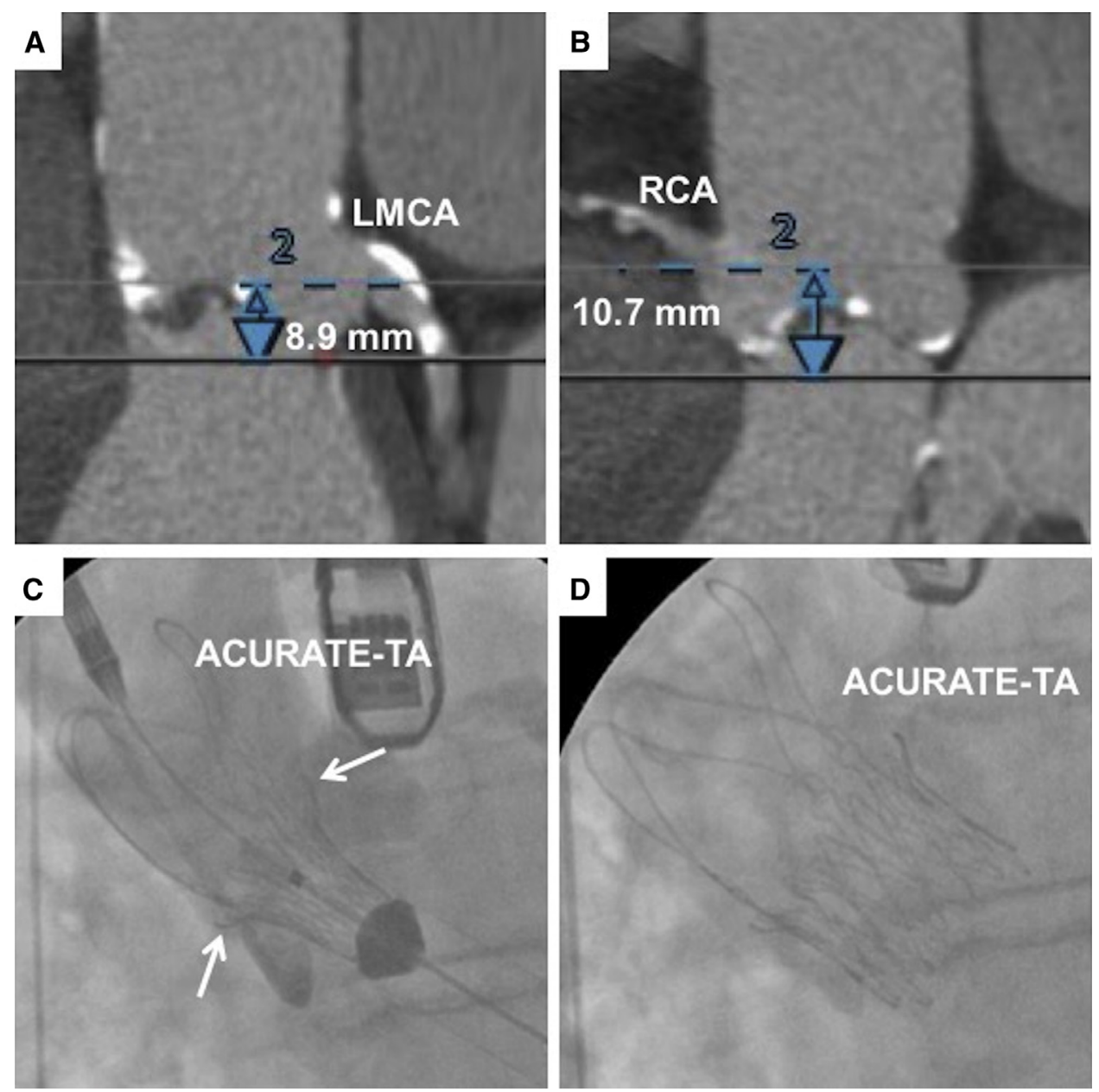

FIGURE 2. Preoperative TAVR CT scan demonstrating a narrow aortic root with low lying left main (A) and right main (B) coronary arteries. During valve deployment (C), the upper crown (arrows) is first released and engages the native aortic valve calcification toward the aortic annulus, away from the native coronary ostia. After final valve release (D), the lower crown seals the left ventricular outflow tract. LMCA, Left main coronary artery; $R C A$, right coronary artery.

the left and right coronary ostia were $10.8 \pm 1.5 \mathrm{~mm}$ and $16.4 \pm 4.1 \mathrm{~mm}$, respectively, with a sinus of Valsalva annular ratio of $1.3 \pm 0.8$. All patients had an angiographically patent left main coronary artery.

\section{Device Safety and Efficacy (Table 3)}

The procedure/device success was achieved in all 30 patients $(100 \%)$, and early safety at 30 days was achieved in 28 of 30 patients $(93.3 \%)$. Of note, no patients experienced any coronary occlusion and no coronary bailout procedures were required. No patients had any valve embolization, annular rupture, or aortic dissection, nor did any patients require conversion to open surgical aortic valve replacement. Immediate postimplant balloon valvuloplasty was used in 8 patients $(27 \%)$ for incomplete stent deployment, high transvalvar gradients, or acute paravalvular leaks. Only 2 patients $(6.7 \%)$ had complications during the procedure; 1 patient $(3.3 \%)$ had apical rupture and required emergency cardiopulmonary bypass for apical repair, whereas another patient $(3.3 \%)$ had a local femoral artery dissection, which was managed conservatively.

\section{Postoperative Complications}

There was $1(3.3 \%)$ in-hospital/30-day mortality. This patient had a successful TAVR and was discharged on the third postoperative day but returned to the hospital 3 weeks later with a diffusely ischemic bowel, and palliative management was chosen. No patients had stroke or transient ischemic attack, nor did any patients have myocardial infarction. Respiratory failure and delirium each occurred in 1 patient $(3.3 \%)$ in our series. Newonset atrial fibrillation or flutter occurred in 6 patients $(20 \%)$, and 1 patient $(3.7 \%)$ required insertion of a permanent pacemaker postoperatively because of a complete atrioventricular block. The median intensive care unit stay and overall hospital length of stay were 1 day (1-1) and 


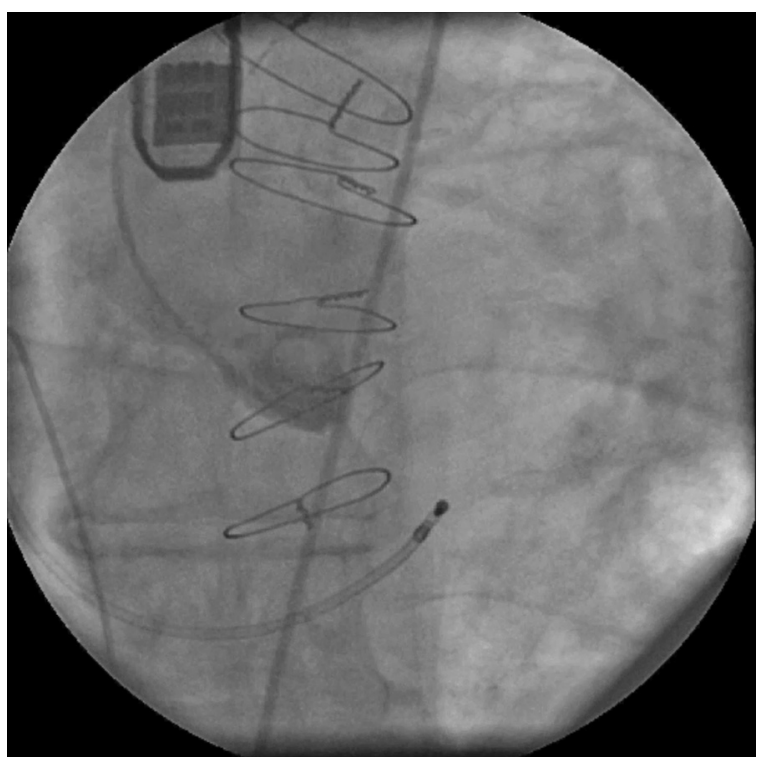

VIDEO 1. Typical Acurate TA (Symetis, Ecublens, Switzerland) implantation in a patient with a small aortic root and low lying left main coronary artery, demonstrating the significant "pull" of the upper crown on the native aortic valve toward the aortic annulus during transcatheter valve deployment. Video available at: http://www.jtcvsonline.org/article/ S0022-5223(16)31678-6/addons.

6 days (5-8), respectively. Detailed postoperative complications are outlined in Table 4.

\section{Survival and Follow-up Outcomes}

Survival at 30 days and 1 year was $97 \%$ and $89 \%$, respectively (Figure 3). There were 3 mortalities during the follow-up period: A 92-year-old woman died of gastrointestinal complications 5 months after TAVI, an 80-yearold woman died of stroke 5 months after TAVI, and a 92year-old woman died as the result of ischemic bowel 13 months after TAVI. At the most recent follow-up, all surviving patients remained in NYHA functional class I and II (Figure 4).

There was a statistically significant reduction in transvalvular gradients from preoperative mean and peak values of $59.2 \pm 16.6 \mathrm{~mm} \mathrm{Hg}$ and $83.5 \pm 30.7 \mathrm{~mm} \mathrm{Hg}$ to $13.8 \pm 6.6 \mathrm{~mm} \mathrm{Hg}(P<.0005)$ and $28.3 \pm 12.1 \mathrm{~mm} \mathrm{Hg}$ $(P<.0005)$ postoperatively, respectively (Figure 5$)$. No patients experienced greater than mild AI, neither paravalvular nor intravalvular, postoperatively or at any point in follow-up (Figure 6).

\section{DISCUSSION}

Coronary obstruction after TAVR remains a challenging complication with much of the published work focused on identifying patient and anatomic risk factors associated with higher risk of coronary obstruction. ${ }^{1-7}$ Coronary protection strategies have been described, including in situ coronary wire cannulation, preloaded left main, and
TABLE 1. Patient characteristics, comorbidities, and risks*

\begin{tabular}{|c|c|}
\hline Patient characteristics & $\mathbf{N}=\mathbf{3 0}$ \\
\hline Age (y) & $85.0 \pm 5.5$ \\
\hline Range & 70.4-96.4 \\
\hline Female & $19(63.3)$ \\
\hline BMI $\left(\mathrm{kg} / \mathrm{m}^{2}\right)$ & $26.4 \pm 5.0$ \\
\hline Diabetes & $9(30)$ \\
\hline Creatinine $(\mu \mathrm{mol} / \mathrm{L})$ & $106 \pm 40$ \\
\hline Dialysis & 0 \\
\hline History of smoking & $10(33.3)$ \\
\hline Hypertension & $27(90)$ \\
\hline Congestive heart failure & $7(23.3)$ \\
\hline Dyslipidemia & $23(76.7)$ \\
\hline COPD & $5(16.7)$ \\
\hline Coronary artery disease & $14(46.7)$ \\
\hline Prior myocardial infarction & $6(20)$ \\
\hline Peripheral vascular disease & $13(43.3)$ \\
\hline Prior stroke & $9(30)$ \\
\hline Prior TIA & $4(13.3)$ \\
\hline Prior atrial fibrillation/flutter & $11(36.7)$ \\
\hline Prior pacemaker & $3(10)$ \\
\hline Porcelain aorta & $9(30)$ \\
\hline Pulmonary hypertension & $21(75)$ \\
\hline Redo & $14(46.7)$ \\
\hline First time redo & $13(43.3)$ \\
\hline Second time redo & $1(3.3)$ \\
\hline Prior CABG & $13(43.3)$ \\
\hline Prior valve & $3(10)$ \\
\hline Prior PCI & $4(13.3)$ \\
\hline \multicolumn{2}{|l|}{ Symptoms } \\
\hline NYHA III/IV & $30(100)$ \\
\hline \multicolumn{2}{|l|}{$\mathrm{CCS}$} \\
\hline 0 & $11(36.7)$ \\
\hline 1 & $10(33.3)$ \\
\hline 2 & $2(6.7)$ \\
\hline 3 & $7(23.3)$ \\
\hline 4 & 0 \\
\hline Syncope & $4(13.3)$ \\
\hline STS score & $8.4 \pm 6.0$ \\
\hline euroSCORE II & $9.7 \pm 7.2$ \\
\hline
\end{tabular}

BMI, Body mass index; COPD, chronic obstructive pulmonary disease; TIA, transient ischemic attack; $C A B G$, coronary artery bypass grafting; $P C I$, percutaneous coronary intervention; NYHA, New York Heart Association; CCS, Canadian Cardiovascular Society; STS, Society of Thoracic Surgeons; euroSCORE, European System for Cardiac Operative Risk Evaluation. *All data are presented as mean \pm standard deviation (SD) or $\mathrm{n}(\%)$ unless otherwise noted.

underdeployed stents with a variable degrees of success when acute coronary obstruction occurs. ${ }^{3,5}$ The most commonly accepted strategy in most patients at high risk for coronary obstruction is simply avoidance of TAVR. ${ }^{5}$ We report our experience in treating patients at higher risk for coronary obstruction, with lower lying coronary artery ostia and narrow aortic roots, with the Symetis Acurate TA prosthesis, which also represented the first North American experience with this prosthesis.

Although it was early in our learning curve, procedural outcomes were good and complications were infrequent. 
TABLE 2. Preoperative transthoracic echocardiography and computed tomography details*

\begin{tabular}{|c|c|}
\hline Preoperative echocardiography and CT details & $\mathbf{N}=\mathbf{3 0}$ \\
\hline \multicolumn{2}{|l|}{ Transthoracic echocardiography } \\
\hline Mean gradient $(\mathrm{mm} \mathrm{Hg})$ & $57.7 \pm 19.7$ \\
\hline Peak gradient $(\mathrm{mm} \mathrm{Hg})$ & $81.0 \pm 34.2$ \\
\hline $\operatorname{LVEF}(\%)$ & $61.8 \pm 8.7$ \\
\hline $\operatorname{RVSP}(\mathrm{mm} \mathrm{Hg})$ & $42.3 \pm 10.1$ \\
\hline Annular diameter (mm) & $29 \pm 4$ \\
\hline \multicolumn{2}{|l|}{ AI grade } \\
\hline None & $3(10)$ \\
\hline Trace & $4(13.3)$ \\
\hline Mild & $14(46.7)$ \\
\hline Moderate & $9(30)$ \\
\hline Severe & 0 \\
\hline \multicolumn{2}{|l|}{ Mitral insufficiency grade } \\
\hline None & $4(13.3)$ \\
\hline Trace & $3(10)$ \\
\hline Mild & $8(26.7)$ \\
\hline Mild-moderate & $8(26.7)$ \\
\hline Moderate & $6(20)$ \\
\hline Moderate-severe & $1(3.3)$ \\
\hline \multicolumn{2}{|l|}{ TR grade } \\
\hline None & $1(3.3)$ \\
\hline Trace & $5(16.7)$ \\
\hline Mild & $8(26.7)$ \\
\hline Mild-moderate & $9(30)$ \\
\hline Moderate & $7(16.7)$ \\
\hline \multicolumn{2}{|l|}{ TAVI CT } \\
\hline Annulus max (mm) & $26.5 \pm 2.7$ \\
\hline Annulus min (mm) & $21.7 \pm 2.2$ \\
\hline Annulus mean $(\mathrm{mm})$ & $24.1 \pm 2.1$ \\
\hline Annulus circumference (mm) & $75.7 \pm 6.2$ \\
\hline Annulus area $\left(\mathrm{mm}^{2}\right)$ & $419.7 \pm 73.9$ \\
\hline Sinus of Valsalva:annular ratio $(\mathrm{mm})$ & $1.3 \pm 0.8$ \\
\hline Left coronary height $(\mathrm{mm})$ & $10.8 \pm 1.5$ \\
\hline Right coronary height $(\mathrm{mm})$ & $16.4 \pm 4.1$ \\
\hline
\end{tabular}

We believe that the uniqueness of the stent frame design of the Acurate TA valve helps to mitigate the risk of coronary obstruction in this higher-risk population. ${ }^{17,18}$ The upper crown "engages" and compresses the native aortic valve calcium toward the annulus, away from the coronary ostia (Video 1). This provides the implanter with reassuring tactile feedback, unique to its transapical design. The upper and lower crown complex provide added axial stabilization (in addition to the usual radial stabilization of most TAVR valves), self-adjustment during final release, and excellent sealing to prevent important paravalvular leak. These design advantages reinforce the utility of the transapical approach with excellent device control and the ability to pull the native aortic calcium away from the coronary ostia with this stent design; however, this could be at the cost of
TABLE 3. Operative details*

\begin{tabular}{lc}
\hline Operative details & $\mathbf{N}=\mathbf{3 0}$ \\
\hline Urgency & \\
Elective & $23(76.7)$ \\
Urgent & $7(23.3)$ \\
Transapical & $30(100)$ \\
Valve size & \\
Small & $12(40)$ \\
Medium & $13(43.3)$ \\
Large & $5(16.7)$ \\
Preprocedural balloon & $29(96.7)$ \\
Preprocedural balloon size & \\
$18 \times 4$ & $3(10)$ \\
$20 \times 4$ & $5(16.7)$ \\
$22 \times 4$ & $11(36.7)$ \\
$24 \times 4$ & $1(3.3)$ \\
$25 \times 4$ & $9(30)$ \\
Postprocedural balloon & $8(26.7)$ \\
Postprocedural balloon size & \\
$20 \times 4$ & $2(6.7)$ \\
$22 \times 4$ & $2(6.7)$ \\
$25 \times 4$ & $4(13.3)$ \\
Valve in valve & $1(3.3)$ \\
\hline$*$ All data are presented as mean \pm SD or $n(\%)$ unless otherwise noted. &
\end{tabular}

slightly increased transvalvular gradients. Although the newer-generation Symetis Acurate-Neo device has a better hemodynamic profile and can be implanted both

TABLE 4. Postoperative complications and outcomes*

\begin{tabular}{lc}
\hline \multicolumn{1}{c}{ Postoperative complications } & $\mathbf{N}=\mathbf{3 0}$ \\
\hline In-hospital/30-d mortality & $1(3.3)$ \\
Myocardial Infarction & 0 \\
Stroke/TIA & 0 \\
Bleeding & $1(3.3)$ \\
Life-threatening bleeding & $1(3.3)$ \\
Major bleeding & $1(3.3)$ \\
Minor bleeding & 0 \\
Acute kidney injury & 0 \\
Vascular complication & $1(3.3)$ \\
Major vascular complication & 0 \\
Minor vascular complication & $1(3.3)$ \\
Conduction disturbances & \\
New LBBB & 0 \\
New pacemaker & $1(3.7)$ \\
New atrial fibrillation/flutter & $6(20)$ \\
Respiratory failure & $1(3.3)$ \\
Delirium & $1(3.3)$ \\
Sepsis & 0 \\
Any of 10 & $3(10)$ \\
Length of stay & \\
ICU LOS, median $(I Q R)$ & $1(1-1)$ \\
Prolonged ICU stay $(>4 \mathrm{~d})$ & $1(3.3)$ \\
Hospital LOS, median $(I Q R)$ & $6(5-8)$ \\
Prolonged hospital stay $(>10 \mathrm{~d})$ & $4(13.3)$ \\
\hline
\end{tabular}

TIA, Transient ischemic attack; $L B B B$, left bundle branch block; $I C U$, intensive care unit; $I Q R$, interquartile range; $L O S$, length of stay. *All data are presented as mean $\pm \mathrm{SD}$ or $\mathrm{n}(\%)$ unless otherwise noted. 


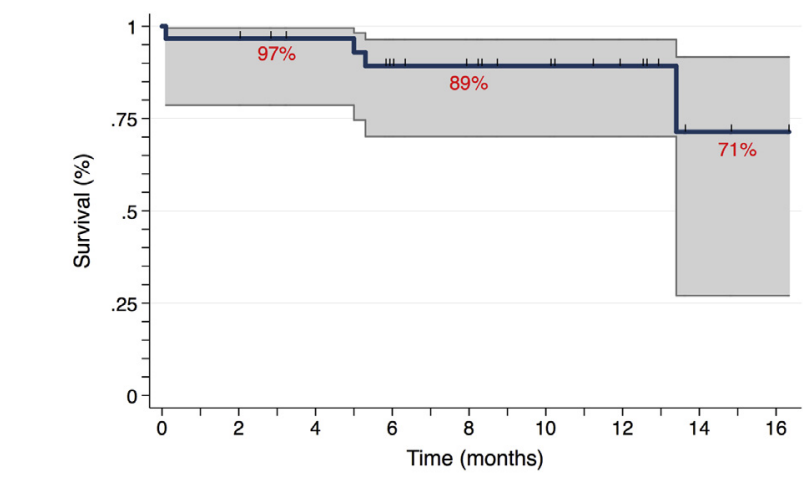

Number at-risk $\begin{array}{llllllll}30 & 29 & 26 & 21 & 18 & 14 & 10 & 3\end{array}$

FIGURE 3. One-year Kaplan-Meier survival curve.

transfemorally and transapically, its advantages in reducing the risk of coronary obstruction are yet unknown.

Our results are in keeping with previously reported European results. $8,10,11,13$ Kempfert and colleagues 8,9 reported their initial experience with 40 patients treated at multiple German centers with the Symetis Acurate TA valve with a 30-day mortality of $12.5 \%$, stroke rate of $5 \%$, and moderate or greater paravalvular leak rate of $3.4 \%{ }^{8,9}$ More recently, an Acurate TA registry of 250 consecutive patients treated at 17 sites in Germany, Italy, Switzerland, and Argentina reported a 30-day mortality rate of $6.8 \%$, stroke rate of $2.8 \%$, and a moderate or greater paravalvular leak rate of $2.3 \% .{ }^{11}$ Of note, there was only 1

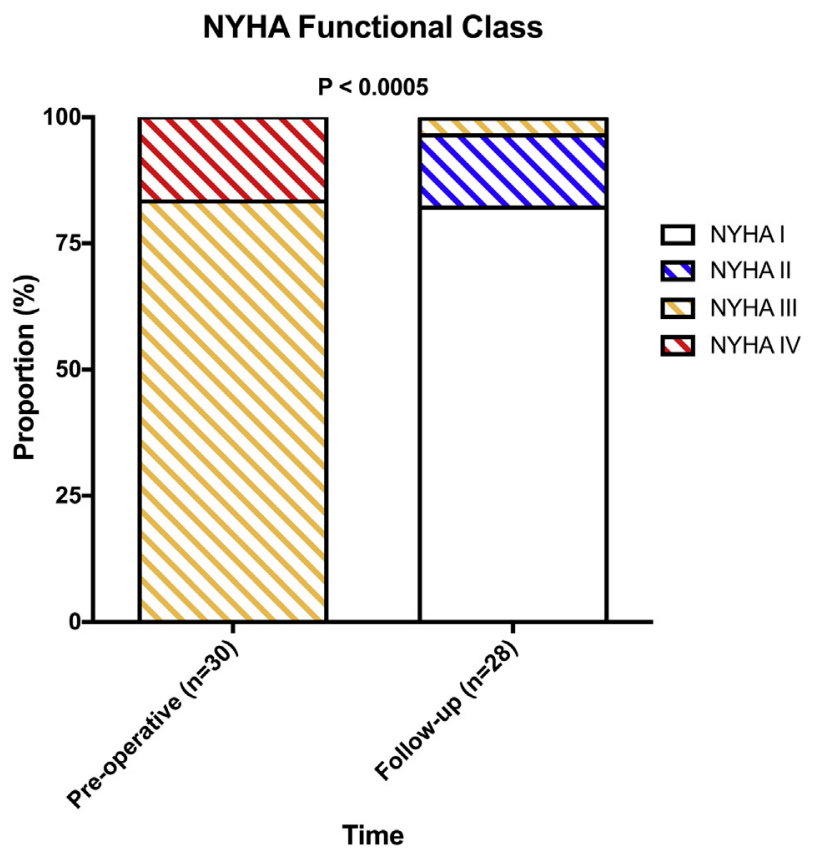

FIGURE 4. NYHA functional class before TAVR and at last follow-up period. NYHA, New York Heart Association.

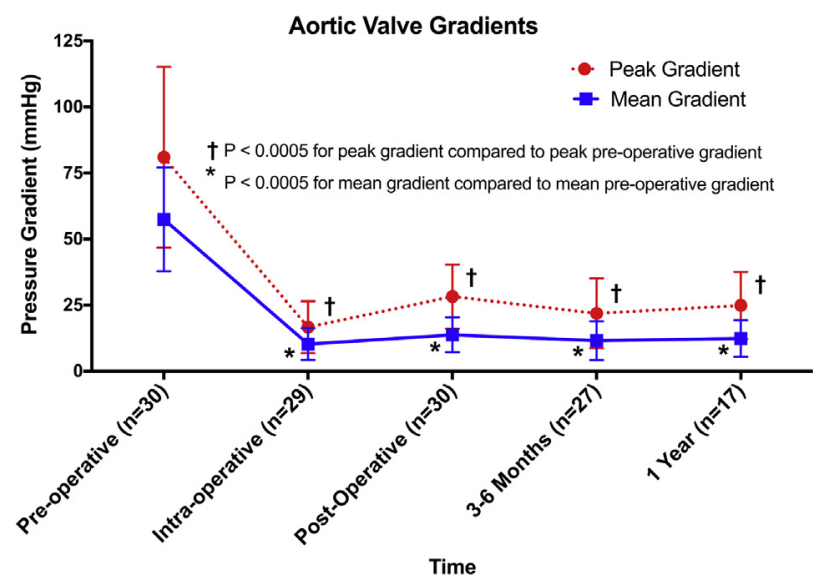

FIGURE 5. Mean and peak transvalvular gradients measured by transthoracic echocardiography.

case of coronary impingement reported in any of these 3 series.

\section{Study Limitations}

This analysis has a number of important limitations, including the well-described limitations of a small, single-center, retrospective case series, and should be interpreted for hypothesis generation alone. Despite selecting patients with higher-risk anatomic features for coronary impingement, we acknowledge that coronary obstruction remains relatively uncommon and could have been missed in our series. We also acknowledge the growing reluctance in North America to perform transapical TAVR procedures, which may affect the generalizability of our experience in other centers. Finally, we liberally used postimplant balloon valvuloplasty for incomplete stent deployment, high residual gradients, or acute paravalvular leaks, which may have explained our extremely low paravalvular leak rate results.

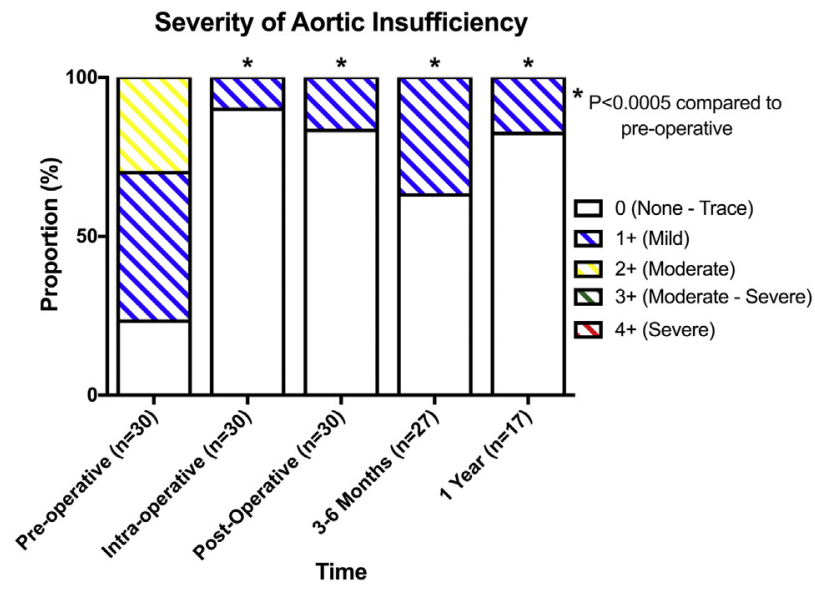

FIGURE 6. AI as measured by transthoracic echocardiography. 


\section{CONCLUSIONS}

We have reported our early experience with the Symetis Acurate TA in 30 consecutive patients at higher risk for coronary obstruction. This inaugural North American experience with the Acurate TA demonstrated high procedural success and excellent short-term and 1-year patient outcomes. Continued follow-up in a larger patient population is necessary to evaluate the longer-term survival and hemodynamic outcomes.

\section{Webcast}

You can watch a Webcast of this AATS meeting presentation by going to: http://webcast.aats.org/2016/Video/Tuesday/ 05-17-16_Ballroom_III_0735_Chu-800.mp4.

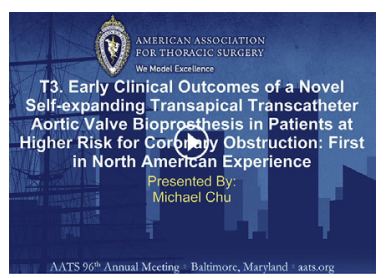

\section{Conflict of Interest Statement}

M.W.A.C.: Medtronic, Canada (consultant), Edwards Lifesciences (consultant), Symetis (speakers bureau), Livanova (consultant, speakers bureau). B.K.: Medtronic, Canada (consultant), Symetis (speakers bureau), Johnson and Johnson (consultant). All other authors have nothing to disclose with regard to commercial support.

\section{References}

1. Ribeiro HB, Nombela-Franco L, Urena M, Mok M, Pasian S, Doyle D, et al. Coronary obstruction following transcatheter aortic valve implantation: a systematic review. JACC Cardiovasc Interv. 2013;6:452-61.

2. Ribeiro HB, Webb JG, Makkar RR, Cohen MG, Kapadia SR, Kodali S, et al. Predictive factors, management, and clinical outcomes of coronary obstruction following transcatheter aortic valve implantation: insights from a large multicenter registry. J Am Coll Cardiol. 2013;62:1552-62.

3. Abramowitz Y, Chakravarty T, Jilaihawi H, Kashif M, Kazuno Y, Takahashi N, et al. Clinical impact of coronary protection during transcatheter aortic valve implantation: first reported series of patients. EuroIntervention. 2015;11:572-81.

4. Naoum C, Blanke P, Dvir D, Pibarot P, Humphries K, Webb J, et al. Clinical outcomes and imaging findings in women undergoing TAVR. J Am Coll Cardiol Img. 2016;9:483-93.

5. Dvir D, Leipsic J, Blanke P, Ribeiro HB, Kornowski R, Pichard A, et al. Coronary obstruction in transcatheter aortic valve-in-valve implantation: preprocedural evaluation, device selection, protection, and treatment. Circ Cardiovasc Interv. 2015;8:e002079.

6. Dvir D, Webb JG, Bleiziffer S, Pasic M, Waksman R, Kodali S, et al. Transcatheter aortic valve implantation in failed bioprosthetic surgical valves. JAMA. 2014;312:162-70.

7. Dvir D, Webb J, Brecker S, Bleiziffer S, Hildick-Smith D, Colombo A, et al. Transcatheter aortic valve replacement for degenerative bioprosthetic surgical valves: results from the global valve-in-valve registry. Circulation. 2012;126: 2335-44.

8. Kempfert J, Rastan AJ, Beyersdorf F, Schönburg M, Schuler G, Sorg S, et al. Trans-apical aortic valve implantation using a new self-expandable bioprosthesis: initial outcomes. Eur J Cardiothorac Surg. 2011;40:1114-9.

9. Kempfert J, Möllmann H, Walther T. Symetis ACURATE TA ${ }^{\mathrm{TM}}$ valve. EuroIntervention. 2012;8(Suppl Q):Q102-9.
10. Kempfert J, Treede H, Rastan AJ, SchSchönburg M, Schuler G, Sorg S, et al Transapical aortic valve implantation using a new self-expandable bioprosthesis (ACURATE TA ${ }^{\mathrm{TM}}$ ): 6-month outcomes. Eur J Cardiothorac Surg. 2013;43:52-6.

11. Kempfert J, Holzhey D, Hofmann S, Girdauskas E, Treede H, Schröfel H, et al First registry results from the newly approved ACURATE TA ${ }^{\text {TM }}$ TAVI system. Eur J Cardiothorac Surg. 2015;48:137-41.

12. Kempfert J, Meyer A, Kim WK, Van Linden A, Arsalan M, Blumenstein J, et al. Comparison of two valve systems for transapical aortic valve implantation: a propensity score-matched analysis. Eur J Cardiothorac Surg. 2016;49:486-92.

13. Seiffert M, Conradi L, Kloth B, Koschyk D, Schirmer J, Schnabel RB, et al Single-centre experience with next-generation devices for transapical aortic valve implantation. Eur J Cardiothorac Surg. 2015;47:39-45.

14. Kappetein PA, Head SJ, Genereux P, Piazza N, van Mieghem NM Blackstone EH, et al. Updated standardized endpoint definitions for transcatheter aortic valve implantation. The Valve Academic Research Consortium-2 consensus document. J Thorac Cardiovasc Surg. 2013;145:6-23.

15. Bagur R, Rodés-Cabau J, Doyle D, De Larochellière R, Villeneuve J, Lemieux J, et al. Usefulness of TEE as the primary imaging technique to guide transcatheter transapical aortic valve implantation. JACC Cardiovasc Imaging. 2011;4:115-24.

16. Walther T, Falk V, Kempfert J, Borger MA, Fassl J, Chu MW, et al. Transapical minimally invasive aortic valve implantation; the initial 50 patients. Eur J Cardiothorac Surg. 2008;33:983-8.

17. Nagendran J, Catrip J, Diamantouros P, Teefy P, Kiaii B, Chan I, et al. Symetis valve implantation in failing freestyle with close proximity between coronary ostia and annulus. Ann Thorac Surg. 2015;99:e87-8.

18. Bagur R, Kiaii B, Teefy PJ, Diamantouros P, Harle C, Goela A, et al Transcatheter ACURATE-TA aortic valve implantation in a patient with a previous mechanical mitral valve. Ann Thorac Surg. 2015;100:e115-7.

Key Words: transcatheter aortic valve implantation, transcatheter aortic valve replacement, coronary obstruction, transapical, aortic valve

\section{Discussion}

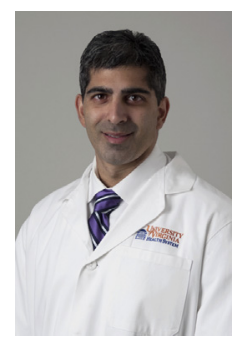

Dr G. Ailawadi (Charlottesville, Va). Is there a cutoff as to what's too low for coronary obstruction? You mentioned the mean distance from the annulus to the left and right coronaries. Is there a cutoff or do you feel safe with this device and not other devices?

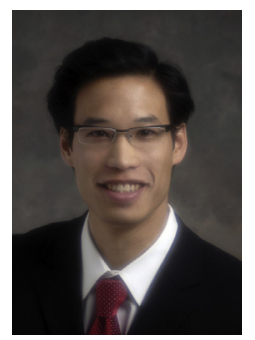

Dr Chu. We've treated patients with coronary clearance of down to $6 \mathrm{~mm}$ above the annulus with this device. We have turned away a couple of patients, particularly those with the valve-in-valve in whom the annulus has been approximately 2 or $3 \mathrm{~mm}$, but we've treated patients successfully down to $6 \mathrm{~mm}$.

Dr Ailawadi. That's important because many of the potential valve-in-valve cases that we end up treating surgically are because the coronaries are just too low for safe TAVR implantation. I was impressed with the overall low pacemaker rate based on at least the design that you showed us. It seemed like a lot of the stent sits underneath the annulus. Can you tell us more about the design features and why you think that might be? 
Dr Chu. There are 2 things to consider. One is that $10 \%$ of our patients had a pacemaker beforehand, so the $3.3 \%$ postimplant pacemaker rate is probably somewhat artificially low. Second, the radial force of this valve is lower than the radial force that you might expect with a Sapien or a CoreValve, so that's probably why the pacemaker rate remains low even though the lower crown does sit where you would expect it to normally cause a pacemaker. Those are probably the 2 key design features.

In terms of why the paravalvular leak rates are so low is that there is a long, robust skirt with the lower crown in this prosthesis that effectively seals the left ventricular outflow tract, even with irregular calcium. This really helps to reduce significant paravalvular leak.

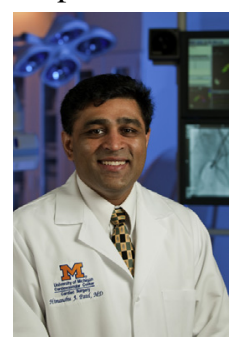

Dr H. Patel (Ann Arbor, Mich). What this valve seems to need is a lot more manipulation of the native aortic valve, and obviously the concern would be stroke. So as Wilson just mentioned earlier, stroke is not reported as high in most studies unless you actively go looking for it. In this study, how did you assess for stroke? Was there a neurologist or imaging?

Dr Chu. Good point. We assess for stroke on a clinical basis. We do have a neurologist as part of our TAVR team if need be. You're right, there's subclinical stroke not identified in many of our TAVR cases. We don't routinely assess all of our patients with the battery of neurocognitive testing that we perform for TAVR clinical trials. I think a more robust means of neuroassessment is important, but at this time, in our system, not always practical. This is a limitation of our data.

The manipulation of the aortic valve itself, intuitively you would think again that would cause more stroke as well. But what you saw was a single pull and then a release, so it may not be that much more manipulation than what you would see with a Sapien or a CoreValve deployment.

Dr G. Ailawadi (Charlottesville, Va). Overall, these results are impressive. Do you think something like this could really challenge a transfemoral approach or does this have its own boutique mix like the bad peripheral access?

Dr Chu. Well, obviously in our program, patients who have good transfemoral access receive a transfemoral approach. We're not trying to select patients away from a transfemoral approach. But I think this is a good reason why technology that's transapically based is still useful to keep in our back pockets. In our TAVR team, we try and celebrate every approach that we have, and we don't select on the basis of politics. We try and select on the basis of what each patient needs. Specifically in the patients with low coronary heights and bad femoral access, we think this is an excellent option. 